Gut, 1985, 26, 1233-1239

\title{
Antibody mediated hepatocyte injury in methyl dopa induced hepatotoxicity
}

\author{
J NEUBERGER, J G KENNA, K NOURI ARIA, AND ROGER WILliams
}

From the Liver Unit, King's College Hospital and School of Medicine and Dentistry, Denmark Hill, London

SUMmARY To investigate the mechanisms underlying the hepatotoxicity induced by methyl dopa, we have examined sera from nine patients with liver damage following the use of the drug for evidence of sensitisation to drug altered liver cell membrane antigens using both immunofluorescence and antibody dependent cell mediated cytotoxicity. Five sera induced significant cytotoxicity to hepatocytes isolated from rabbits pretreated with methyl dopa after exposure to the mixed function oxidase inducer, Arachlor 1254. Sera from 10 patients on methyl dopa but with normal liver function and 32 patients with other drug and viral induced liver damage, gave normal cytotoxicity values. Two of the antibody positive sera gave a specific immunofluorescence pattern at the periphery of human hepatocytes when tested on liver biopsy specimens taken from patients taking methyl dopa. These findings are consistent with the view that immune mechanisms directed against drug associated antigens are involved in severe liver damage from methyl dopa administration and that metabolic activation of the drug is implicated in the generation of drug associated antigen. The need for a combination of immune and metabolic factors may explain the rarity of this condition.

Both minor and severe forms of liver damage have been reported in patients receiving methyl dopa for the treatment of hypertension. The former consists of asymptomatic, and often transient, rises of serum transaminases and according to various reports is found in two to $10 \%$ of patients receiving the drug. ${ }^{1-3}$ The abnormalities are usually manifest within four weeks of starting the drug. The clinically overt and more severe forms of hepatotoxicity are encountered much less frequently and the total number of such cases in the literature, according to Zimmerman, ${ }^{4}$ is less than 85 . This type of liver damage, which may take the form of acute hepatitis, chronic active hepatitis or cholestasis, ${ }^{2}$ occurs more commonly in women ${ }^{5}$ and there is not the same close temporal relationship between the time of onset of overt clinical hepatic injury, which in 50\% of cases occurs after four weeks. ${ }^{6}$ Indeed, such methyl dopa related liver disease has been reported as becoming apparent after five or more years' drug ingestion. ${ }^{7}$ There is an appreciable mortality with

Address for correspondence: Dr J Neuberger, Liver Unit, King 's College Hospital and School of Medicine and Dentistry. Denmark Hill. London SE5 8RX.

Received for publication 13 December 1984 the clinically overt type of hepatotoxicity of around $10 \% .^{2}$

Whereas the more common minor rises in serum transaminases may be attributable to a 'predictable' type of hepatotoxicity, the rarity of the overt form and the lack of correlation with the dose of drug would be more consistent with a host idiosyncratic mechanism. That the idiosyncratic liver damage, as with other similar drug reactions, is related, at least in part, to immune mechanisms is suggested by the other immune mediated disorders associated with methyl dopa ingestion, such as autoimmune haemolytic anaemia, generation of autoantibodies and disorders of lymphocyte function, ${ }^{8-10}$ although these features are not necessarily found in those patients who develop severe liver disease.

During the past 10 years we have seen nine patients with severe liver damage after receiving methyl dopa therapy, including five cases with fulminant hepatic failure. In this report we describe the presence of antibodies reacting with methyl dopa induced liver cell membrane antigens. We were also able to show the presence of the corresponding antigen in biopsy specimens from some of these patients using immunofluorescence techniques. 


\section{Methods}

\section{PATIENTS}

The nine patients had been referred to the Liver Unit between 1973 and 1982 and had been taking methyl dopa (750-2000 mg daily) for periods ranging from seven weeks to three years before the onset of jaundice (Table). All but two were women and ages ranged from 40-78 years. Three of the patients presented with features of an acute hepatitis, with pale stools, dark urine and jaundice, and in only one (case 3) were there no pre-ictal symptoms of anorexia, nausea and weight loss. Liver histology showed features of an acute hepatitis with an inflammatory cell portal infiltration and occasional foci of necrosis. One patient with histological features of chronic active hepatitis on biopsy (case 4) presented with a three months' history of anorexia, nausea, and abdominal discomfort. $\mathrm{He}$ gave a 10 year history of diabetes mellitus that was controlled by diet alone. All of these patients stopped taking the drug on the appearance of jaundice, and liver function tests improved and transaminases returned to normal.

The remaining five patients presented with a short history of nausea, anorexia, and jaundice with subsequent rapid deterioration and appearance of signs of hepatic encephalopathy in each instance within seven days of the onset of symptoms. Death occurred after the appearance of signs of grade IV ${ }^{11}$ encephalopathy two to six weeks from the time of the first symptom. At necropsy liver histology showed features of massive hepatic necrosis, most marked in the centrilobular areas with cholestasis and, in three, with early fibrosis in the portal tracts.

None of the patients was taking other known hepatotoxic agents and daily ethanol intake in all was less than $60 \mathrm{~g}$. Sera from all patients were tested and found negative for evidence of infection with hepatitis viruses A and B, cytomegalovirus, EpsteinBarr virus and toxoplasmosis. One of the patients (case 1) with an acute hepatitis like illness, had an associated haemolytic anaemia with a positive Coomb's test at the time of illness which subsequently resolved. Autoantibodies (smooth muscle, nuclear or gastric parietal cell) were present in six of the nine patients. For a control group serum samples were examined from 10 patients who were receiving methyl dopa for the treatment of hypertension and in whom no abnormalities of liver function had developed. Dose of methyl dopa ranged from 500 to $2000 \mathrm{mg}$ daily and medication had been taken from six to 24 months before testing. There were six men and ages ranged from 26-62 years (median 49 years). Serum was also examined from two patients with pre-existing liver disease (autoimmune chronic active hepatitis and primary biliary cirrhosis) who had been given methyl dopa $750 \mathrm{mg}$ daily for six months on account of hypertension but with no change in liver function.

In addition serum was examined from 12 normal volunteers and 32 patients with other forms of liver disease (alcoholic liver disease (10); liver failure from halothane (six); paracetamol overdose (six); rifampicin/isoniazid hepatotoxicity (four); hepatitis A viral infection (four); presumed hepatotoxicity from ampicillin (one); and carbon tetrachloride toxicity (one).)

\section{PREPARATION OF SERA}

Sera was stored at $-20^{\circ} \mathrm{C}$ until required. They were heat inactivated at $56^{\circ} \mathrm{C}$ for 30 minutes. Antibodies

Table Clinical and laboratory data of the nine patients with methyl dopa associated disease

\begin{tabular}{|c|c|c|c|c|c|c|c|}
\hline $\begin{array}{l}\text { Case } \\
\text { (no) }\end{array}$ & $\begin{array}{c}\text { Age } \\
(y r)\end{array}$ & Sex & $\begin{array}{l}\text { Daily dose } \\
\text { of } \alpha \text {-methyl dopa } \\
\text { (mg) }\end{array}$ & $\begin{array}{l}\text { Duration } \\
\text { of therapy } \\
\text { before } \\
\text { symptoms }\end{array}$ & $\begin{array}{l}A S T \\
I U / l\end{array}$ & $\begin{array}{l}P T \\
\text { Sec } \\
\text { prolonged }\end{array}$ & Auto antibodies \\
\hline \multicolumn{8}{|c|}{ Acute hepatitis } \\
\hline 1 & 57 & $\mathbf{F}$ & 750 & $3 \mathrm{yr}$ & 81 & +2 & Neg \\
\hline 2 & 69 & $\mathbf{M}$ & 750 & $3 \mathrm{yr}$ & 59 & +1 & GPC \\
\hline 3 & 78 & $\mathbf{F}$ & 750 & 7 weeks & 952 & NT & ANA \\
\hline \multicolumn{8}{|c|}{ Chronic active hepatitis } \\
\hline 4 & 55 & $\mathbf{M}$ & 750 & $3 \mathrm{yr}$ & 140 & +1 & SMA \\
\hline \multicolumn{8}{|c|}{ Fulminant hepatic failure } \\
\hline 5 & 50 & $\mathbf{F}$ & 750 & $4 \mathrm{mo}$ & 3630 & $3 \mathrm{~min}$ & Neg \\
\hline 6 & 47 & $\mathbf{F}$ & 2000 & $1 \mathrm{yr}$ & 400 & $3 \mathrm{~min}$ & Neg \\
\hline 7 & 49 & $\mathbf{F}$ & 750 & $4 \mathrm{mo}$ & 440 & +7 & ANA \\
\hline 8 & 40 & $\mathbf{F}$ & 1500 & $3 \mathrm{mo}$ & 2070 & +27 & GPC \\
\hline 9 & 63 & $\mathbf{F}$ & 750 & $2 \mathrm{mo}$ & 102 & +21 & ANA \\
\hline
\end{tabular}

AST $=$ Aspartate transaminase, PT $=$ Prothrombin time,, $\mathrm{GPC}=$ Gastric parietal cell antibody, SMA $=$ Smooth muscle antibody, ANA $=$ Anti-nuclear antibody, NT $=$ Not tested. 
reacting with normal rabbit liver cell components were absorbed by incubating $200 \mu \mathrm{l}$ serum with an equal volume of hepatocytes, isolated by collagenase digestion (see below) at room temperature for 45 minutes. After centrifugation, the serum was further absorbed with hepatocytes at $4^{\circ} \mathrm{C} .{ }^{12}$ The serum was then diluted 1:100 in RPMI 1640 (Gibco) before use in the assay.

PRETREATMENT OF RABBITS

Female New Zealand white rabbits, weight $2-2 \cdot 5$ $\mathrm{kg}$, were given either no treatment or methyl dopa (2-methyl-3(3-4 dihydroxyphenyl)-L-alanine; Sigma Chemical Co), dissolved in saline, $50 \mathrm{mg} / \mathrm{kg} /$ day, by intraperitoneal injection for three days. This dose was chosen because it would give levels comparable with those used in the in vitro studies. ${ }^{13}$

In order to study the effects of enzyme induction rabbits were pretreated with either phenobarbitone $(30 \mathrm{mg} / \mathrm{kg} / \mathrm{day}$ for three days by intraperitoneal injection 48 hours before administration of methyl dopa) or Arachlor 1254 (Analabs, Northaven, Conn, USA) $(500 \mathrm{mg} / \mathrm{kg}$ dissolved in $5 \mathrm{ml}$ corn oil by intraperitoneal injection 48 hours before methyl dopa). As a control, rabbits were given Arachlor in corn oil alone and killed four days later. Histological examination of the livers showed no evidence of cell damage, although those animals receiving corn oil (with or without Arachlor) showed some fatty infiltration.

\section{ISOLATION OF HEPATOCYTES}

Rabbits were killed by intravenous injection of 340 mg pentabarbitone and 1000 IU preservative free heparin. The liver was removed in a sterile fashion and minced, and hepatocytes were isolated by overnight incubation, with $0.1 \%$ collagenase Type IV (Sigma Chemical Co.) in $10 \%$ heat inactivated fetal calf serum and 90\% RPMI 1640. After washing, the cells were seeded into microculture test wells at a dilution of 100 hepatocytes per well. Viability of hepatocytes, assessed by trypan blue exclusion, was greater than $90 \%$. The purity of hepatocytes, as shown by electron microscopy was greater than $95 \%$.

\section{CYTOTOXICITY ASSAY}

The cells were maintained at $37^{\circ} \mathrm{C}$ in an atmosphere of $95 \%$ oxygen, $5 \%$ carbon dioxide. After overnight incubation to allow hepatocytes to adhere to the tissue culture plates, the supernatant was removed and the cells were incubated for two hours with $10 \mu \mathrm{l}$ of either diluted test serum or $10 \%$ fetal calf serum to allow any antibody present in the serum to coat the target cells. The supernatant was removed and, after washing with $10 \mu \mathrm{l}$ of $10 \%$ fetal calf serum, the hepatocytes were incubated for a further 36 hours with lymphocytes isolated from normal healthy individuals (by dextran sedimentation, Ficoll-Triosil density centrifugation and petri dish incubation) to allow antibody coated target cell lysis by the $\mathrm{K}$ cell population. ${ }^{12}$ The ratio of lymphocytes to hepatocytes was 100:1. The plates were then inverted for two hours to allow removal of non-adherent cells and after washing, the cells were fixed and the number of adherent hepatocytes counted visually without the observer having knowledge of the source of the serum. A minimum of 10 wells were counted. The percentage cytotoxicity was calculated from the formula:

$$
\% \text { cytotoxicity }=\frac{\mathrm{NC}-\mathrm{NT}}{\mathrm{NC}} \times 100,
$$

where NC is mean number of cells in control wells and NT is the corresponding number for the 10 test wells.

The upper limit of normal $(28 \%)$ was calculated as two standard deviations above the mean for 30 control sera in preliminary experiments. Cytoxicity values above this figure were considered to be significantly raised.

\section{DETECTION OF METHYL DOPA ASSOCIATED}

ANTIGENS ON LIVER BIOPSIES

Human liver microsomal fraction was prepared from normal human liver by mincing thoroughly and homogenising in 10 volumes of $0 \cdot 25 \mathrm{~mol} / 1$ sucrose, 5 $\mathrm{mM}$ TRIS $\mathrm{pH} 8 \cdot 0$, after which the total microsomal fraction was isolated by differential centrifugation. ${ }^{14}$ Sufficient sera from four patients was available (cases 2, 3, 6, 7) together with sera from two patients with untreated autoimmune chronic active hepatitis without any ingestion of methyl dopa, were diluted 1:4 in RPMI. These diluted sera were absorbed three times with human liver microsomal fraction $(2 \mathrm{mg}$ protein $/ \mathrm{ml})$ by incubation for 45 minutes at room temperature, then for 45 minutes at $4^{\circ} \mathrm{C}$. This was followed by one hour centrifugation at $100000 \mathrm{~g}$ at $4^{\circ} \mathrm{C}$ to sediment the membrane fraction and bound antibody. Liver biopsies were obtained from two patients (5 and 7) with serological evidence of methyl dopa induced liver damage, two patients without circulating antibodies (nos 2 and 6), two patients receiving methyl dopa with pre-existing liver disease and four patients with alcoholic liver disease. Paraffin embedded sections were treated with xylene for 10 minutes at room temperature and then rehydrated in phosphate buffered saline (PBS) by five minutes washing in $100 \%, 95 \%$, and $75 \%$ ethanol. The biopsies were then incubated for 45 minutes at room temperature with either serum or RPMI and, after three washings in PBS, for a 
further 45 minutes in 1:40 FITC-labelled anti-human immunoglobulin (Wellcome Laboratories Ltd). After a further three washings in PBS the biopsies were examined under ultraviolet light with incident light.

\section{Results}

\section{CYTOTOXICITY STUDIES}

Sera from five of the nine patients with methyl dopa associated hepatotoxicity induced significant cytotoxicity to hepatocytes isolated from rabbits pretreated with Arachlor and methyl dopa (Fig. 1). None of the sera from patients with other forms of liver disease or those taking methyl dopa with no evidence of liver damage induced significant cytotoxicity to these hepatocytes. Cytotoxicity was observed when only one (case 5) of these sera was incubated with target cells isolated from animals treated with methyl dopa alone or methyl dopa after phenobarbitone pretreatment but none when Arachlor was given alone without methyl dopa.

In order to show that the cytotoxicity assay was antibody mediated, the five sera giving significant cytotoxicity were incubated with Arachlor and methyl dopa pretreated hepatocytes as described above. These antibody coated target cells were then incubated for a further two hours with $2 \mu \mathrm{g} \mathrm{F}(\mathrm{ab})_{2}$ fragment to human Fc of IgG (prepared according to Nisowoff $e a^{15}$ ) in order to prevent binding of the effector cell to the target cell through the lymphocyte $\mathrm{Fc}$ receptor. This resulted in a decrease in induced cytotoxicity from $44 \pm 15 \%$ (mean \pm SD) to $8 \pm 8 \%$ ( $p<0.05$ Wilcoxon's paired rank test). In a further series of experiments the five sera were absorbed with hepatocytes isolated from rabbits pretreated with Arachlor and methyl dopa and then used in the assay. This resulted in a significant reduction in cytotoxicity (to $6 \pm 4 \%, \mathrm{p}<0.05$ ). None of the sera induced significantly cytotoxicity when incubated with cells isolated from rabbits previously exposed to $1 \%$ halothane in oxygen for 45 minutes, another example of a target cell expressing a drug related antigen. ${ }^{12}$ The methyl dopa related antibody was present in the one patient with methyl dopa associated chronic active hepatitis and two of the three with an acute hepatitis. There was no difference between those patients with or without antibody with respect to age, sex, duration of amount of methyl dopa ingested.

\section{IMMUNOFLUORESCENCE STUDIES}

When two sera from patients with circulating methyl dopa related antibodies, absorbed with human microsomes, were incubated with liver sections from the two patients with methyl dopa hepatitis and circulating antibodies a specific pattern of fluoresc-
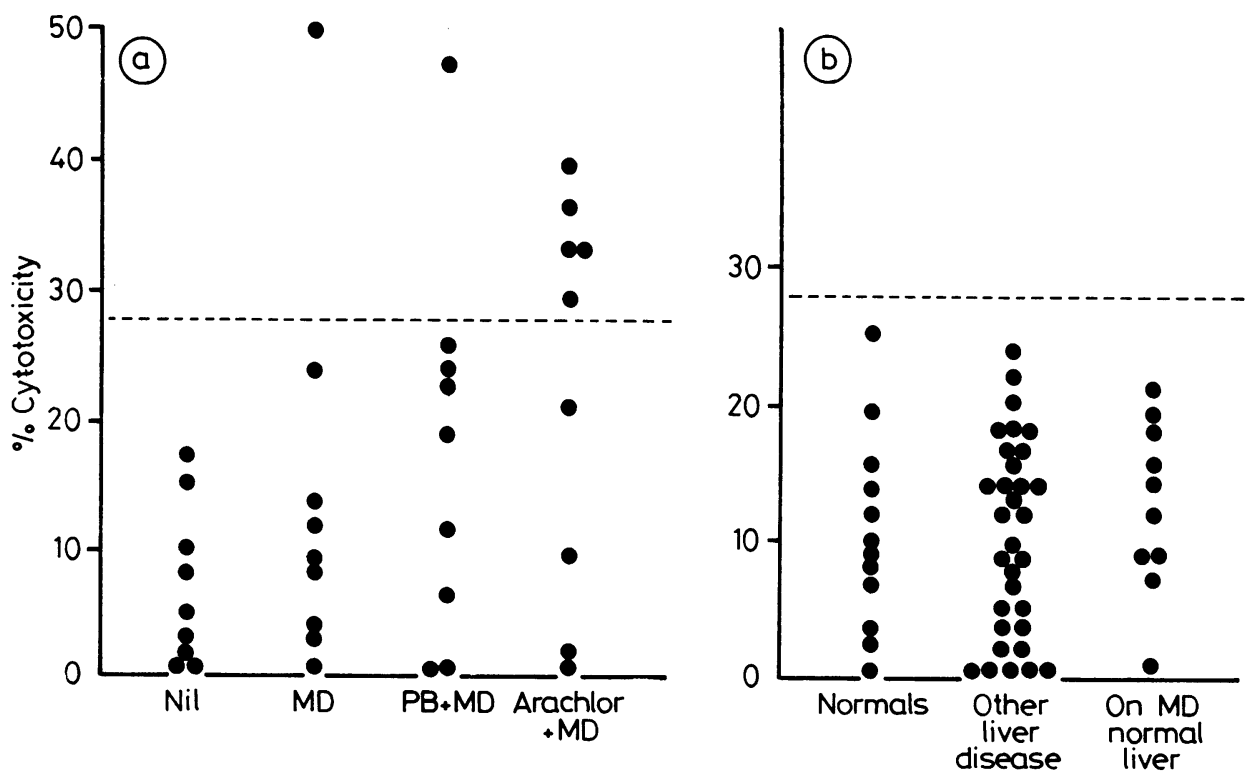

Fig. 1 Cytotoxicity induced by: (a) serum from patients with methyl dopa induced liver damage to hepatocytes isolated from rabbits pretreated with methyl dopa, or after phenobarbitone or Arachlor, and: (b) Serum from patients in the control groups to hepatocytes pretreated with Arachlor and methyl dopa. 
ence was seen (Fig. 2a), with increased fluorescence at the periphery of hepatocytes. In contrast, much less staining was seen when the same sera were incubated with liver tissue from patients with methyl dopa liver damage but without circulating antibody, from two normal subjects or from patients with other liver damage but taking methyl dopa (Fig. 2b). Furthermore, no staining was observed with all these tissues using either normal sera or else two sera from patients with methyl dopa induced liver damage but without circulating antibodies.

\section{Discussion}

The finding that just over half the patients with methyl dopa induced hepatotoxicity have a circulating antibody which reacts with the antigen present on the surface of liver cells from rabbits pretreated with Arachlor and then given methyl dopa is of considerable interest in relation to the possible mechanism of hepatotoxicity. The specificity of antibody was shown since it was not found in the serum of patients receiving the drug with no evidence of liver disease nor in any other form of liver disease. The finding in the cytotoxicity assay that the antibody reacts with a determinant present on the rabbit cell membrane indicates that a similar, if not identical, antigen is generated in humans. This is given additional support by the immunofluorescence studies.

The exact mechanism by which methyl dopa ingestion results in the generation of the new or neo-antigen remains to be established. It is not because of a direct effect of the drug on the plasma membrane because enzyme induction with Arachlor is required for the appearance of the antigen. Orally administered methyl dopa is metabolised by the liver and intestine. ${ }^{16}$ In vitro studies have shown that the drug is metabolised by both human and rat liver microsomes, by the cytochrome P450 system, with consequent covalent binding to cellular macromolecules. ${ }^{17}$ This covalent binding is inhibited by a variety of agents, including glutathione, ascorbic acid and superoxide dismutase ${ }^{18}$ consistent with the oxidation of methyl dopa by cytochrome P450generated superoxide anions to a reactive quinone or semi-quinone. Covalent binding of reactive metabolites to cellular macromolecules may cause alteration to the conformation or the quarternary structure of proteins and thus render them immunogenic, or else the metabolite itself may act as a hapten. As the proteins of the cell surface membrane are synthesised on the endoplasmic reticulum, any interaction with reactive metabolites at this site may result in the immunogen being translocated to the cell surface through the usual biosynthetic routes, thus resulting in the appearance of a drug membrane related antigen. ${ }^{19}$ The importance of the semiquinone is emphasised by the demonstration that lymphocytes from patients with methyl dopa hepatitis are sensitised to the quinone derivative but not the parent drug. ${ }^{20}$ Arachlor itself is weakly hepatotoxic $^{6}$ and the possibility that the antigen is generated as a result of in vivo interaction of two weak direct hepatotoxins cannot be totally discounted. Nonetheless, no antibody was detected using hepatocytes treated with Arachlor alone and histological examination of the rabbit liver showed no evidence of hepatic necrosis, the fatty infiltration being due entirely to the corn oil vehicle.

The possibility that the appearances of the antibody is secondary to the liver damage is unlikely, because circulating antibody was not detected in those patients receiving methyl dopa but who had other causes of liver damage. Sensitisation to hepatocyte components can occur secondary to toxic liver injury ${ }^{21}{ }^{22}$ but such sensitisation is short lived and analogous circulating antibodies have not been demonstrated $^{1221}$ in paracetamol toxicity. If, however, immune mechanisms are important in the pathogenesis of methyl dopa induced liver damage, then the lack of such demonstration in nearly half the patients must be explained. One possible explanation for the fact the antibody is not detectable in the serum is that the antibody is either complexed with the antigen, as an immune complex, or else is bound on the liver cell membrane. This explanation has a parallel in halothane hepatotoxicity where sequential serum samples taken from patients with halothane hepatitis may show a progressive fall in the degree of cytotoxicity induced to halothane treated hepatocytes. Thus samples taken within three or four days before death may fail to induce significant cytotoxicity to such hepatocytes (Neuberger, unpublished data). A further explanation is that the assay is not sensitive enough.

Routes of metabolism are affected by a wide variety of factors, including genetic and environmental. ${ }^{6}$ The fluorescence studies show that the drug related antigen was demonstrable only in those patients with circulating antibody, indicating that host factors are required to generate the antigen. Thus the expression of the antigen in certain patients could be due either to an idiosyncratic route of methyl dopa metabolism or else to exogenous factor, inducing drug metabolism by a relatively minor pathway. As methyl dopa itself can affect cytochrome $\mathrm{P} 450$ activity, ${ }^{23}$ it is possible that the drug itself may, in susceptible individuals, alter its own metabolic pathways. Furthermore, methyl dopa can affect the response to the altered antigens by decreasing suppressor lymphocyte function. ${ }^{10}$ So 

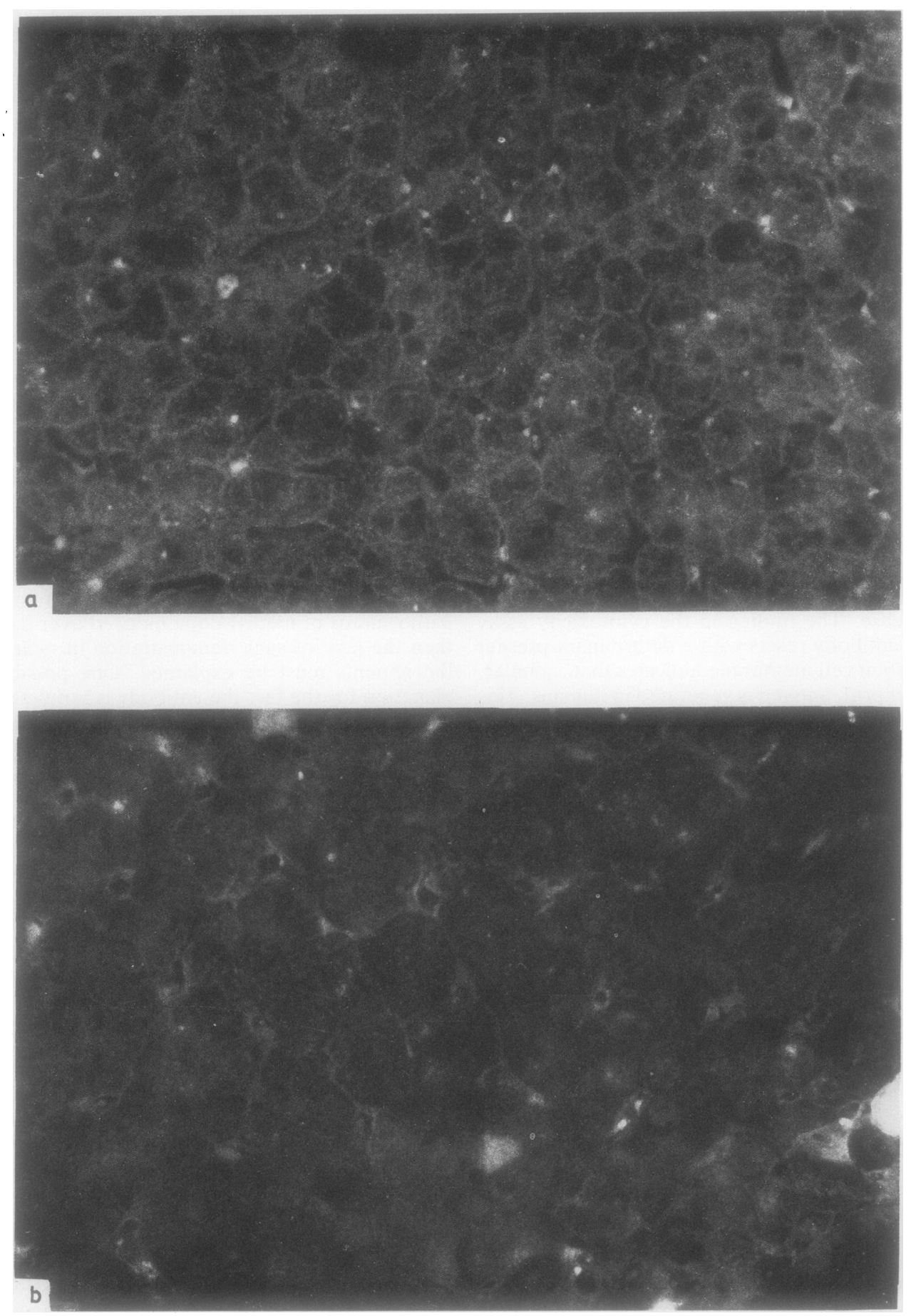

Fig. 2 Tissue section immunofluorescence, induced by a serum from a patient known to contain the methyl dopa antibody reacting with a liver biopsy section from: (a) A patient with methyl dopa induced liver disease and: (b) A patient with primary biliary cirrhosis, receiving methyl dopa. 
it may be that the common transient and mild hepatotoxicity is mediated by a direct toxic mechanism and the appearance of the less common, overt and potentially fatal drug toxicity, may be dependent both on abnormal metabolism of the drug to generate the antigen and the effect on immune function to respond to that antigen. The wide variety of liver damage observed is analogous to that found after hepatitis B viral infection where hepatotoxic cell damage is mediated by immune attack on antigen on the hepatocyte membrane: a decreased immune response leads to minimal liver damage and persistence of surface viral markers, whereas an enhanced immune response leads to massive liver cell necrosis and fulminant hepatic failure. ${ }^{24}$ With many other drug reactions of an idiosyncratic nature, a similar spectrum of liver damage is seen.

The high incidence of patients in this series with fulminant hepatic failure associated with use of the drug, must to some extent reflect the pattern of referral consequent on the specialist interest of this Unit in fulminant hepatic failure. There have been a few other instances of fulminant hepatic failure induced by methyl dopa and it is to be stressed that all other causes of fulminant hepatic failure had been excluded in the present cases; and, furthermore, the frequency of the cytotoxic antibody was as high in this clinical group as in the non-fulminant hepatic failure cases.

Dr James Neuberger is a Wellcome Senior Clinical Research Fellow. We are grateful to Dr P Richardson, Senior Lecturer in in Cardiology, for certain of the serum samples.

\section{References}

1 Nickerson M, Ruedy J. Antihypertensive agents and the drug therapy of hypertension. In: Goodman LS, Gilman AG, Koelle GB, eds. The pharmacological basis of therapeutics 5th ed. Macmillan: New York, 1975: 2: 1350-68.

2 Rodman JS, Deutsch DJ, Gutman SI. Methyl dopa hepatitis. A report of six cases and a review of the literature. Am J Med 1976; 60: 941-8.

3 Cacace LG, Cohen M. Alpha methyl dopa (Aldomet) hepatitis. Review of a case and review of the literature. Drug Intell Clin Pharmacol 1976; 10: 144-62.

4 Zimmerman HJ, Maddrey WC. Toxic and drug induced hepatitis. In: Schiffe Schiff $\mathrm{L}$, ed. Disease of the liver. Lippincott: New York, 1983. 621-2.

5 Leonard SW, Goffard RW, Humphrey DC. Treatment of hypertension with methyl dopa alone or combined with Guanethedine. A report of 63 cases. Am Heart J 1965; 69: 610-8.

6 Zimmerman HJ. In: Hepatotoxity. Appleton Century
Croft: New York, 1978.

7 Arranto AJ, Sotaniemi EP. Morphological alterations in patients with methyl dopa induced liver disease after short and long term exposure. Scand J Gastroenterol 1981; 16: 853-63.

8 Worlledge SM, Carstairs KC, Dacie JV. Autoimmune haemolytic anaemia associated with methyl dopa therapy. Lancet 1966; 2: 135-9.

9 Maddley WC, Boitnott JE. Severe hepatitis from methyl dopa. Gastroenterology 1975; 63: 351-60.

10 Kirtland HH, Mohler DN, Horwitz DA. Methyl dopa inhibition of suppressor lymphocyte function. $N$ Engl J Med 1980; 302: 825-32.

11 Trey C, Davidson CS. In: Popper H, Schaffner F, eds. Progress in liver disease. Grune and Stratton: New York, 1970; 282-306.

12 Vergani D, Mieli-Vergani G, Alberti A, et al. Antibodies on the surface of halothane altered rabbit hepatocytes in patients with severe halothane associated hepatitis. $N$ Engl J Med 1980; 303: 66-71.

13 Dybing E. Organ and species differences in microsomal activation of methyl dopa. Drug Metab Disp 1976; 4: 513-6.

14 Touster O, Aronson NN, Dulaney JT, Hendrickson H. Isolation of rat liver membrane proteins. $J$ Cell Biol 1970; 47: 608-14.

15 Nisowoff A, Wissler FC, Lipman LN, Woerney DI. Separation of unvalent fragments from the bivalent antibodies molecule by reduction of desulphide bonds. Arch Biochem Biopys 1960; 89: 230-43.

16 Myhre E, Rugstad H, Hansen T. Clinical pharmacokinetics of methyl dopa. Clin Pharmacol 1982; 7: 221-3.

17 Dybing E. Activation of methyl dopa, paracetamol and frusemide by human liver microsomes. Acta Pharmacol Toxicol 1977; 41: 89-93.

18 Dybing E, Nelson SD, Mitchell JR, Sasame HA, Gilette JR. Oxidation of methyl dopa and other catechols by cytochrome P.450 generates superoxide. Possible mechanism of methyl dopa hepatitis. Mol Pharmacol 1976; 12: 911-20.

19 Morre DJ, Kartenbecr J, Franke WW. Membrane flow and interconversions among endomembranes. Biochem Biophys Acta 1979; 554: 71-152.

20 Torres AC, Tong MJ, Chang K, Schweitzer I. Lymphocyte stimulation in methyl dopa related hepatitis. [Abstract]. Clin Res 1976; 24: 106A.

21 Smith CI, Cooksley WGE, Powell L. Cell mediated immunity to liver antigens in toxic liver injury. I. Occurence and specificity. Clin Exp Immunol 1980; 39: 607-17.

22 Smith CI, Cooksley WGE, Powell L. Cell mediated immunity to liver antigens in toxic liver injury. II. Role in pathogenesis of liver disease. Clin Exp Immunol 1980; 39: 618-23.

23 Ylkallio A, Sotaniemi EA. Drug metabolism and liver function after methyl dopa withdrawal. $\mathrm{Br} J$ Clin Pharmacol 1980; 10: 115-9.

24 Gimson AES, Tedder R, White YS, Eddleston AWLF, Williams R. IgM anti-hepatitis $B$ core and other serological markers in fulminant hepatitis B. [Abstract]. Gut 1981; 22: A871-2. 